\title{
769.
}

\section{ON A FORMULA RELATING TO ELLIPTIC INTEGRALS OF THE THIRD KIND.}

[From the Proceedings of the London Mathematical Society, vol. XIII. (1882), pp. 175, 176. Presented May 11, 1882.]

THE formula for the differentiation of the integral of the third kind

$$
\Pi=\int_{0} \frac{d \phi}{\left(1+n \sin ^{2} \phi\right) \Delta}
$$

in regard to the parameter n, see my Elliptic Functions, Nos. 174 et seq., may be presented under a very elegant form, by writing therein

$$
\sin ^{2} \phi=x=\operatorname{sn}^{2} u, \quad \sin \phi \cos \phi \Delta=y=\operatorname{sn} u \operatorname{cn} u \operatorname{dn} u,
$$

and thus connecting the formula with the cubic curve

$$
y^{2}=x(1-x)\left(1-k^{2} x\right) \text {. }
$$

The parameter must, of course, be put under a corresponding form, say $n=-\frac{1}{a}$, where $a=\operatorname{sn}^{2} \theta, \quad b=\operatorname{sn} \theta \operatorname{cn} \theta \operatorname{dn} \theta$, and therefore $(a, b)$ are the coordinates of the point corresponding to the argument $\theta$. The steps of the substitution may be effected without difficulty, but it will be convenient to give at once the final result and then verify it directly. The result is

We, in fact, have

$$
\frac{d}{d \theta} \frac{b}{a-x}-\frac{d}{d u} \frac{y}{x-a}=k^{2}(a-x) .
$$

$$
\frac{d x}{d u}=2 \operatorname{sn} u \operatorname{cn} u \operatorname{dn} u=2 y,
$$


769] ON A FORMULA RELATING TO ELLIPTIC INTEGRALS OF THE THIRD KIND. 341 and thence

that is,

$$
y \frac{d x}{d u}=2 y^{2}
$$

$$
y \frac{d x}{d u}=2 x\left[1-\left(1+k^{2}\right) x+k^{2} x^{2}\right]
$$

Also

and hence

$$
\begin{aligned}
\frac{d y}{d u} & =\operatorname{cn}^{2} u \operatorname{dn}^{2} u-\operatorname{sn}^{2} u \operatorname{dn}^{2} u-k^{2} \operatorname{sn}^{2} u \operatorname{cn}^{2} u \\
& =1-2\left(1+k^{2}\right) x+3 k^{2} x^{2}
\end{aligned}
$$

$$
\begin{aligned}
& \frac{d}{d u} \frac{y}{x-a}=\frac{1}{(a-x)^{2}}\left\{(x-a) \frac{d y}{d u}-y \frac{d x}{d u}\right\} \\
& =\frac{1}{(a-x)^{2}}\left\{-x-a+2\left(1+k^{2}\right) a x+k^{2} x^{3}-3 k^{2} a x^{2}\right\} .
\end{aligned}
$$

Interchanging the letters, we have

$$
\frac{d}{d \theta} \frac{b}{a-x}=\frac{1}{(a-x)^{2}}\left\{-x-a+2\left(1+k^{2}\right) a x+k^{2} a^{3}-3 k^{2} a^{2} x\right\}
$$

and hence, subtracting,

$$
\begin{aligned}
\frac{d}{d \theta} \frac{b}{a-x}-\frac{d}{d u} \frac{y}{x-a} & =\frac{1}{(a-x)^{2}}\left\{k^{2} a^{3}-3 k^{2} a^{2} x+3 k^{2} a x^{2}-k^{2} x^{3}\right\} \\
& =\frac{1}{(a-x)^{2}} k^{2}(a-x)^{3} \\
& =k^{2}(a-x),
\end{aligned}
$$

which is the required result. 